\title{
ESTUDO DE CASO: LEVANTAMENTO DAS MANIFESTAÇÕES PATOLÓGICAS APARENTES EXISTENTES EM UMA UNIVERSIDADE DE CASCAVEL - PR
}

\author{
PAGANIN, RICARDO \\ Engenheiro Civil \\ Centro Universitário Assis Gurgacz \\ Paraná; Brasil \\ engpaganin@gmail.com
}

\author{
PERES, MARIA VÂNIA DO NASCIMENTO \\ Engenheira Civil \\ Centro Universitário Assis Gurgacz \\ Paraná; Brasil \\ vaniaperes@gmail.com
}

\author{
STRASSBURGER, FLÁVIA \\ Engenheira Civil \\ Centro Universitário Assis Gurgacz \\ Paraná; Brasil \\ flaviastrassburger@hotmail.com
}

\author{
FELTEN, DÉBORA \\ Engenheira Civil \\ Centro Universitário Assis Gurgacz \\ Paraná; Brasil \\ deboraf@fag.edu.br
}

\author{
RACHID, LIGIA ELEODORA FRANCOVIG \\ Engenheira Civil \\ Centro Universitário Assis Gurgacz \\ Paraná; Brasil \\ ligia@ fag.edu.br
}

\author{
KOPROWSKI, LUCAS E. TAVARES \\ Acadêmico de Engenharia Civil \\ Centro Universitário Assis Gurgacz \\ Paraná; Brasil \\ lucaskkoprowski@gmail.com
}

\section{RESUMO}

Nos últimos anos as ocorrências de manifestações patológicas em construções tiveram um aumento significativo, tendo em vista a multiplicação de empreendimentos, agravada pela falta de mão de obra qualificada. Durante ou após o término das obras várias falhas construtivas são visíveis, prejudicando assim a utilização e a aparência da obra, desvalorizando-a. Este trabalho teve por objetivo levantar as manifestações patológicas aparentes existentes em um edifício de uma universidade, tendo por base a identificação do problema, a sugestão da causa e a indicação de um método de reparo. Foram levantadas in loco as manifestações patológicas em um prédio de três pavimentos destinado a salas de aula, em uma universidade localizada na cidade de Cascavel - PR, juntamente com verificações bibliográficas e especificações técnicas, além disso para apresentação dos dados foi elaborado o mapeamento dos problemas patológicas e a identificação da frequência dos mesmos. Através do levantamento observou-se que em $96 \%$ das unidades vistoriadas há descolamento do revestimento cerâmico, sendo também constatado que em $82 \%$ das unidades há manifestação de problemas com infiltração, as fissuras em lajes são recorrentes em $57 \%$ das unidades visitadas, foram identificadas fissuras nas paredes em $43 \%$ das unidades e eflorescência em $41 \%$. Pode-se ainda constatar que a inspeção visual é um processo simples, porém que fornece muitas informações que possibilitam verificar o estado de conservação e a identificação de manifestações patológicas, para que estas sejam tratadas evitando-se assim maiores danos à edificação e maiores transtornos aos usuários.

Palavras-chave: patologia, causas, reparo, universidade.

\section{ABSTRACT}

In recent years, the occurrence of pathological manifestations in constructions has increased significantly, due to the multiplication of enterprises, aggravated by the lack of qualified labor. During or after the completion of the works several constructive failures are visible, thus impairing the use and appearance of the work, devaluing it. This work aimed to survey the apparent pathological manifestations existing in a university building, based on the identification of the problem, the suggestion of the cause and the indication of a repair method. The pathological manifestations were raised in loco in a three pavements building for classrooms, in a university located in the city of Cascavel - PR, along with bibliographic checks and technical specifications. In addition, their frequency identification. Through the survey it was observed that in $96 \%$ of the inspected units there is detachment of the ceramic coating, and it was also found that in $82 \%$ of the units there is manifestation of problems with infiltration, slabs cracks are recurrent in $57 \%$ of the units visited, were identified. Cracks in the walls in $43 \%$ of the units and efflorescence in $41 \%$. It can also be seen that the visual inspection is a simple process, but it provides a lot of information that makes it possible to verify the state of 
conservation and the identification of pathological manifestations, so that they can be treated thus avoiding greater damage to the building and greater disorders to users.

Keywords: pathology, causes, repair, university.

\section{INTRODUÇÃO}

Tornou-se frequente o surgimento de falhas construtivas em edificações, em parte isso ocorre em virtude da grande demanda do mercado, pois não há tempo para qualificação da mão de obra, isso culminado com prazos para execução de obras cada vez mais curtos resultam na má execução dos serviços da construção civil. Tal situação pode ser justificada pelo acelerado crescimento da construção civil no Brasil antes da crise econômica, de acordo com dados do Instituto Brasileiro de Geografia e Estatística (IBGE) o setor da construção civil cresceu 1,9\% no quarto trimestre de 2013 enquanto o crescimento do Produto Interno Bruto (PIB) foi de 2,3\% (CÂMARA BRASILEIRA DA INDÚSTRIA DA CONSTRUÇÃO - CBIC, 2013). Esse patamar de crescimento vem sendo projetado para o ano de 2019 e 2020, estimando um crescimento da indústria da construção civil de $2 \%$ e $3 \%$, respectivamente (SINDICATO DA INDÚSTRIA DA CONSTRUÇÃO CIVIL DO ESTADO DE SÃO PAULO - SINDUSCON - SP, 2019).

As falhas construtivas chamadas de manifestações patológicas em construções podem ser interpretadas como o baixo, ou o fim, do desempenho de uma estrutura em relação à estabilidade, estética, uso e principalmente a durabilidade das construções para os fins a que se destinam (SOUZA e RIPPER, 1998).

Para Souza (2008), o conhecimento dos problemas patológicos em edificações é indispensável a todos os trabalhadores da construção civil, começando desde o operário até o engenheiro ou arquiteto. Assim quando se conhece a problemática torna-se mais fácil a identificação de erros e as chances de cometê-los podem ser reduzidas drasticamente.

Os consumidores do mercado da construção civil estão mais exigentes, visto que o acesso à informação está cada vez mais amplo no país, eles conhecem seus direitos e sabem reivindicá-los. Sendo assim, uma grande parte das reclamações dos usuários é referente ao surgimento de manifestações patológicas, sendo elas causadas por cuidados ignorados, erros na execução, erros de projeto e até mesmo má utilização do imóvel (RACHID e BASE, 2011).

Contudo percebe-se a importância de um estudo aprofundado do assunto, pois a busca da qualidade nas construções é grande e deve ser incentivada, visto que estes problemas podem ser evitados ou corrigidos quando se identifica a causa, buscando-se sempre a forma viável tecnicamente e economicamente. Sendo assim, esse trabalho teve por objetivo levantar os problemas patológicos aparentes existentes em uma edificação de três pavimentos de uma universidade, localizada na cidade de Cascavel - PR, a fim de identificar os problemas patológicos, estimar sua frequência, sugerir as causas e indicar um método de reparo para os mesmos.

\section{METODOLOGIA}

\subsection{Caracterização da amostra}

O bloco 2 (dois), assim chamado, é uma construção de três pavimentos com uma estrutura de concreto armado e alvenaria convencional, tendo o formato de um losango. A edificação é destinada basicamente para salas de aula, onde vários cursos oferecidos pela instituição realizam as aulas, possuindo uma área construída de aproximadamente 10.600 $\mathrm{m}^{2}$. No primeiro e segundo pavimento ainda funciona um colégio para aulas do ensino fundamental, médio e preparatório para o vestibular no período matutino e vespertino.

A divisão de salas não é idêntica para os três pavimentos, estes são divididos da seguinte forma: no primeiro pavimento (térreo) funcionam 6 (seis) salas de aula, 2 (dois) laboratórios de informática, 1 (uma) livraria, 1 (uma) sala de vídeo, 02 (duas) salas de recreação, 1 (um) laboratório de fotografia, 1 (uma) secretaria acadêmica, 1 (uma) sala para professores, 1 (uma) lanchonete, 1 (um) estúdio de televisão universitária, 1 (um) auditório com capacidade para 150 (cento e cinquenta) pessoas, 1 (um) banheiro masculino, 1 (um) banheiro feminino e 2 (dois) banheiros unissex para deficientes e 2 (dois) depósito para materiais de limpeza; no segundo pavimento funcionam 20 (vinte) salas de aula, 2 (dois) banheiros masculinos, 2 (dois) banheiros femininos, 2 (dois) banheiros unissex para deficientes, sendo os banheiros divididos em duas extremidades do edifício; no terceiro pavimento funcionam 23 (vinte e três) salas de aula, 2 (dois) banheiros masculinos, 2 (dois) banheiros femininos, 2 (dois) banheiros unissex para deficientes, sendo os banheiros divididos em duas extremidades do edifício. 
A edificação tem uma idade de uso de 8 (oito) anos, e conforme relato da empresa responsável pela construção da edificação, a estrutura vem sendo reparada constantemente, estes reparos são coordenados de acordo com a necessidade de reparação dos danos que surgem, culminados com a disponibilidade de mão de obra para execução dos serviços de reparo e/ou recuperação.

\subsection{Instrumentos e procedimentos para coleta de dados}

A coleta de dados foi realizada por meio do levantamento visual na edificação citada por meio da visita ao local. O objetivo foi realizar um levantamento das manifestações patológicas aparentes decorrentes do uso da edificação e de problemas construtivos. Foram feitos registros fotográficos para mapeamento das manifestações patológicas identificadas, além de um croqui dos problemas identificados, para análise dos dados coletados. Para coleta de dados foi utilizado um formulário o qual continha informações relativas a anamnese da edificação.

As manifestações patológicas foram classificadas de acordo com seu grau de risco, seguindo a Norma de Inspeção Predial do Instituto Brasileiro de Avaliações e Pericias de Engenharia (IBAPE, 2012). A classificação foi dividida em três categorias, sendo:

a) Crítico: risco de provocar danos contra a saúde e segurança das pessoas e do meio ambiente; perda excessiva de desempenho e funcionalidade causando possíveis paralisações; aumento excessivo de custo de manutenção e recuperação; comprometimento sensível de vida útil;

b) Regular: risco de provocar a perda parcial de desempenho e funcionalidade da edificação sem prejuízo à operação direta de sistemas, e deterioração precoce;

c) Mínimo: risco de causar pequenos prejuízos à estética ou atividade programável e planejada, sem incidência ou sem a probabilidade de ocorrência dos riscos críticos e regulares, além de baixo ou nenhum comprometimento do valor imobiliário.

Foram feitos levantamentos visuais das manifestações patológicas visto que todas as salas de aula foram visitadas e devidamente investigadas, bem como a região externa do bloco. Foram tomados registros fotográficos a fim de facilitar na visualização dos problemas, foi realizada a medição das áreas afetadas, bem como um check list de todas os problemas encontradas e a frequência de sua ocorrência.

\subsection{Análise dos dados}

Através dos resultados obtidos, as manifestações patológicas foram relacionadas com as possíveis causas, e a tabulação da frequência com que estas se manifestam. Foram propostos métodos corretivos de acordo com o tipo de problema encontrado. Para o método de reparo das manifestações patológicas foi levado em consideração materiais de ampla abrangência de mercado, a fim de otimizar o método de reparo para várias regiões.

Para a realização da tabulação da frequência das manifestações patológicas identificadas nos ambientes da edificação e apresentação dos resultados graficamente, considerou-se a seguinte distribuição dos ambientes da edificação: cada sala de aula representa 1 (uma) unidade; o corredor representa 1 (uma) unidade para cada pavimento; cada conjunto de 3 (três) sanitários, masculino, feminino e de deficientes representa uma unidade para cada pavimento; o auditório representa 1 (uma) unidade; cada escada representa 1 (uma) unidade para cada pavimento; as marquises de projeções nas janelas das salas de aula representam 1 (uma) unidade para cada pavimento.

\section{ANÁLISES E DISCUSSÕES}

De acordo com a metodologia proposta, foi realizada uma visita ao local para constatação das manifestações patológicas, assim como seu mapeamento no escopo do edifício, foram feitos registros fotográficos para ilustrar as demandas patológicas. Para melhor entendimento foram separados inicialmente os levantamentos de acordo com os pavimentos da edificação.

\subsection{Manifestações patológicas identificadas na edificação}


Iniciou-se a vistoria pelo terceiro pavimento, sendo de extrema o levantamento visual, onde foram identificadas as diversas manifestações patológicas existentes em várias locais da edificação. Assim o resumo dos problemas encontrados nesse pavimento e a frequência dos mesmos pode ser observado na Figura 1.

\begin{tabular}{|c|c|c|c|}
\hline \multicolumn{4}{|c|}{$3^{\circ}$ Pavimento } \\
\hline $\begin{array}{l}\text { Tipo de manifestação } \\
\text { patológica }\end{array}$ & Frequência & Ambiente & Observações \\
\hline Fissuras & 21 salas e no corredor & Laje & $\begin{array}{l}\text { Foram identificados vários } \\
\text { tipos de fissuras, que em sua } \\
\text { maioria derivam da dilatação } \\
\text { térmica. }\end{array}$ \\
\hline Fissuras & 17 salas e no corredor & Parede & $\begin{array}{l}\text { Foram identificadas fissuras } \\
\text { semelhantes em vários locais. }\end{array}$ \\
\hline Infiltração & $\begin{array}{l}23 \text { salas, corredor, } \\
\text { banheiros e escadas }\end{array}$ & Parede e laje & $\begin{array}{l}\text { A princípio a manifestação } \\
\text { patológica de maior } \\
\text { ocorrência e maior dano } \\
\text { estético com possíveis danos } \\
\text { estruturais. }\end{array}$ \\
\hline $\begin{array}{l}\text { Descolamento do Piso } \\
\text { cerâmico }\end{array}$ & $\begin{array}{l}23 \text { salas, corredor, } \\
\text { banheiros e escadas }\end{array}$ & Piso & $\begin{array}{l}\text { A cerâmica foi instalada } \\
\text { possivelmente fora dos } \\
\text { padrões. }\end{array}$ \\
\hline Eflorescência & 12 salas e corredor & Laje & $\begin{array}{l}\text { Manifestação de eflorescência } \\
\text { em conjunto com fissuras. }\end{array}$ \\
\hline Eflorescência & $\begin{array}{c}06 \text { banheiros e marquises } \\
\text { das janelas }\end{array}$ & Parede & $\begin{array}{l}\text { Manifestação de eflorescência } \\
\text { ao longo do revestimento } \\
\text { cerâmico de pastilhas } \\
\text { existentes. }\end{array}$ \\
\hline
\end{tabular}

Figura 1: Resumo dos problemas patológicos identificados no terceiro pavimento da edificação.

Com o levantamento e a inspeção no local foi identificada uma grande quantidade de manifestações patológicas, após a síntese apresentada na Figura 1, tem-se então a aplicação do formulário de levantamento dos problemas patológicos, conforme proposto na metodologia.

Foi realizada a vitória no segundo pavimento igualmente, e neste, outras manifestações patológicas foram identificadas, o resumo dos problemas encontrados nesse pavimento pode ser observado na Figura 2.

\begin{tabular}{|c|c|c|l|}
\hline \multicolumn{5}{|c|}{$2^{\circ}$ Pavimento } \\
\hline Tipo de Patologia & Frequência & Ambiente & \multicolumn{1}{c|}{ Observações } \\
\hline Fissuras & 14 salas & Laje & $\begin{array}{l}\text { Foram identificados vários tipos } \\
\text { de fissuras, que em sua maioria } \\
\text { derivam da dilatação térmica. }\end{array}$ \\
\hline Fissuras & 07 salas e escadas & Paredes & $\begin{array}{l}\text { Foram identificadas fissuras } \\
\text { semelhantes em vários locais. }\end{array}$ \\
\hline Infiltração & $\begin{array}{c}17 \text { salas, banheiros e } \\
\text { escadas }\end{array}$ & Paredes e lajes & $\begin{array}{l}\text { A manifestação patológica de } \\
\text { maior ocorrencia e maior dano } \\
\text { estético com possíveis danos } \\
\text { estruturais. }\end{array}$ \\
\hline $\begin{array}{c}\text { Descolamento do Piso } \\
\text { cerâmico }\end{array}$ & $\begin{array}{c}20 \text { salas, corredor, } \\
\text { banheiros e escadas }\end{array}$ & Piso & $\begin{array}{l}\text { A cerâmica foi instalada } \\
\text { possivelmente fora dos padrões. }\end{array}$ \\
\hline $\begin{array}{c}\text { Eflorescência } \\
04 \text { salas de aula, banheiros } \\
\text { e marquises das janelas }\end{array}$ & Parede e lajes & $\begin{array}{l}\text { Manifestação de eflorescência ao } \\
\text { longo do revestimento cerâmico } \\
\text { de pastilhas existente. }\end{array}$ \\
\hline
\end{tabular}

Figura 2: Resumo dos problemas patológicos identificados no segundo pavimento da edificação.

Nota-se que as manifestações patológicas que foram levantadas no $2^{\circ}$ pavimento são muito semelhantes às levantadas no $3^{\circ}$ pavimento. Isso demonstra que há uma tendência dos problemas de repetirem em todos os pavimentos da edificação. A vistoria foi realizada igualmente no primeiro pavimento da edificação, que se refere ao pavimento térreo, a vistoria resultou no resumo dos problemas apresentado na Figura 3. 


\begin{tabular}{|c|c|c|l|}
\hline \multirow{2}{*}{ Tipo de Patologia } & Frequência & Ambiente & \multicolumn{1}{c|}{ Observações } \\
\hline Fissuras & 07 salas & Laje & $\begin{array}{l}\text { Foram identificados vários tipos } \\
\text { de fissuras, que em sua maioria } \\
\text { derivam da dilatação térmica. }\end{array}$ \\
\hline Fissuras & 04 salas e escadas & Paredes & $\begin{array}{l}\text { Foram identificadas fissuras } \\
\text { semelhantes. }\end{array}$ \\
\hline Infiltração & $\begin{array}{c}\text { 08 salas, banheiros, } \\
\text { escadas e auditório }\end{array}$ & Paredes e lajes & $\begin{array}{l}\text { A manifestação patológica de } \\
\text { maior ocorrência e maior dano } \\
\text { estético com possíveis danos } \\
\text { estruturais. }\end{array}$ \\
\hline $\begin{array}{c}\text { Descolamento do Piso } \\
\text { cerâmico }\end{array}$ & $\begin{array}{c}20 \text { salas, corredor e } \\
\text { banheiros }\end{array}$ & Piso & $\begin{array}{l}\text { A cerâmica foi instalada } \\
\text { possivelmente fora dos padrões. }\end{array}$ \\
\hline $\begin{array}{c}\text { Eflorescência } \\
\text { 04 salas de aula, banheiros, } \\
\text { auditório e marquises das } \\
\text { janelas }\end{array}$ & Parede & $\begin{array}{l}\text { Manifestação no revestimento } \\
\text { cerâmico de pastilha e na } \\
\text { pintura. }\end{array}$ \\
\hline
\end{tabular}

Figura 3: Resumo dos problemas patológicos identificados no primeiro pavimento da edificação.

Após o levantamento geral dos problemas identificados nos três pavimentos da edificação, pode-se concluir que há um padrão nas manifestações patológicas identificadas. Sendo assim, os erros de projeto, execução, dos materiais utilizados e de utilização se repetiram nos três pavimentos da edificação.

A fissura apresentada na Figura 4 representa uma manifestação patológica muito comum que ocorre em 9 (nove) salas da edificação neste pavimento, é classificada como fissura, pois a abertura não supera $0,5 \mathrm{~mm}$. A provável causa deste problema pode ser a falta de armadura para combater esforços de momentos fletores na parte inferior da laje gerada por uma provável sobrecarga, conforme relata Souza e Ripper (1998), assim as características indicam um erro de projeto na deficiência da especificação da utilização deste tipo de armadura para combater o surgimento das fissuras.
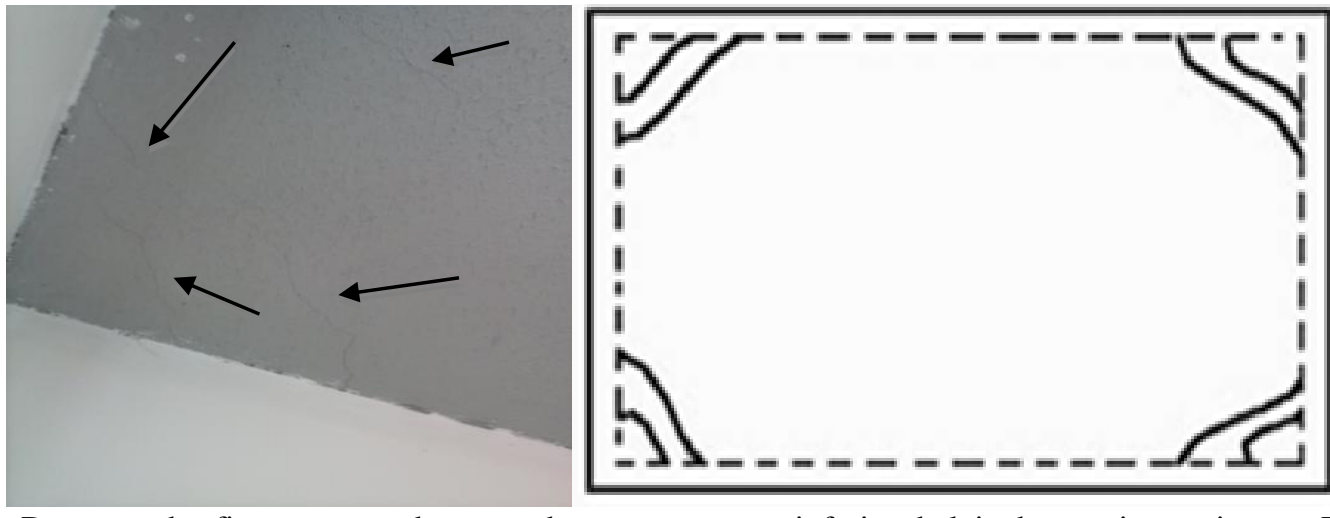

Figura 4: Destaque das fissuras causadas por sobrecarga na parte inferior da laje do terceiro pavimento X modelo proposto por Souza e Ripper (1998).

Além do problema citado anteriormente, em diversas salas e inclusive nos corredores há ocorrências de fissuras que podem ser devido à retração do concreto. Sendo que a retração do concreto é um movimento natural, neste caso o processo de execução e cura da peça estrutural deve ser feito seguindo todas as recomendações técnicas para evitar o surgimento deste tipo de fissura (SOUZA e RIPPER, 1998). Caso o comportamento de retração do concreto não seja levado em consideração tanto no projeto quanto na execução, as possibilidades do desenvolvimento de manifestações patológicas, iguais as observadas na Figura 5 são frequentes. A trinca assim classificada, pois sua abertura supera 0,5 mm é comum em 21 (vinte e uma) salas da edificação neste pavimento e corredores. 

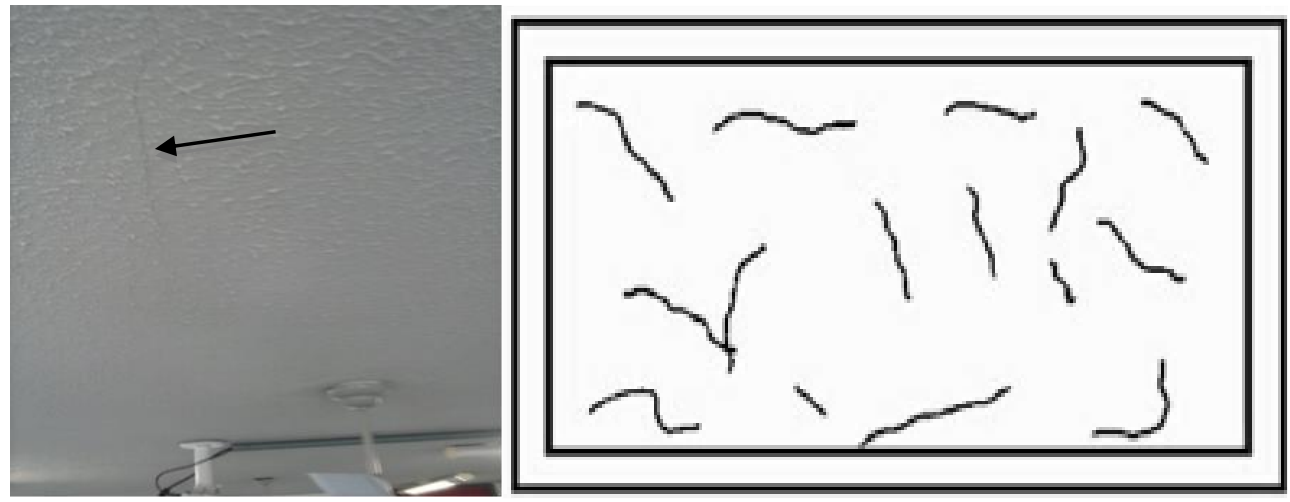

Figura 5: Destaque das fissuras causadas por retração na parte inferior da laje do terceiro pavimento $\mathrm{X}$ modelo proposto por Souza e Ripper (1998).

Ao término do levantamento deste tipo de manifestação patológica e conclusão das possíveis causas pode-se apresentar a seguinte estatística: em 21 (vinte e uma) salas de aula ocorrem problemas de fissuras e trincas na laje. Após a análise e classificação as características destes problemas indicam que essas fissuras e trincas não apresentam risco de ruína da estrutura, porém podem causar desconforto aos usuários da edificação com a sensação de insegurança e propiciar o surgimento de outros problemas como será explanado no item sobre infiltração. Para reparação deste tipo de fissura deve-se aguardar a estabilização do problema e após isso, promover a abertura da fissura em formato "V" e a aplicação de um revestimento flexível a base de poliuretano, sua aplicação pode ser observada na Figura 6.

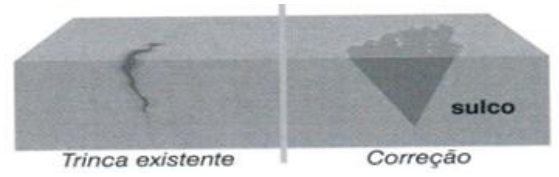

Figura 6: Exemplo da sugestão de reparo das fissuras nas lajes.

Fonte: VEDACIT (2014).

Fissuras em paredes foram encontradas em um número expressivo de salas de aula, porém com a inspeção foi identificado que houve uma reparação recente neste tipo de problema além da manutenção da rede elétrica, contudo ainda pode-se observar o surgimento desta manifestação patológica em 17 (dezessete) salas e no corredor.

Na Figura 7 é possível observar um problema recorrente em 7 (sete) salas de aula, onde a fissura percorre exatamente o caminho da abertura feita na parede para reparos na rede elétrica, este tipo de fissura não apresenta risco estrutural, porém desfavorece o local esteticamente. A causa do surgimento deste problema deu-se devido ao método utilizado para reconstrução da parede após a instalação do condutor, os diferentes materiais tiveram movimentações diferenciais, conclui-se então que o problema surgiu devido um erro de execução. Para o reparo desta fissura pode-se utilizar uma fita de poliéster TNT (Tecido Não Tecido), então a fissura deve ser regularizada e limpa sendo posteriormente coberta totalmente pela fita e sobre a fita deve-se aplicar uma pintura com tinta acrílica, após a secagem da tinta deve-se aplicar uma camada de regularização de massa acrílica (VEDACIT, 2014).

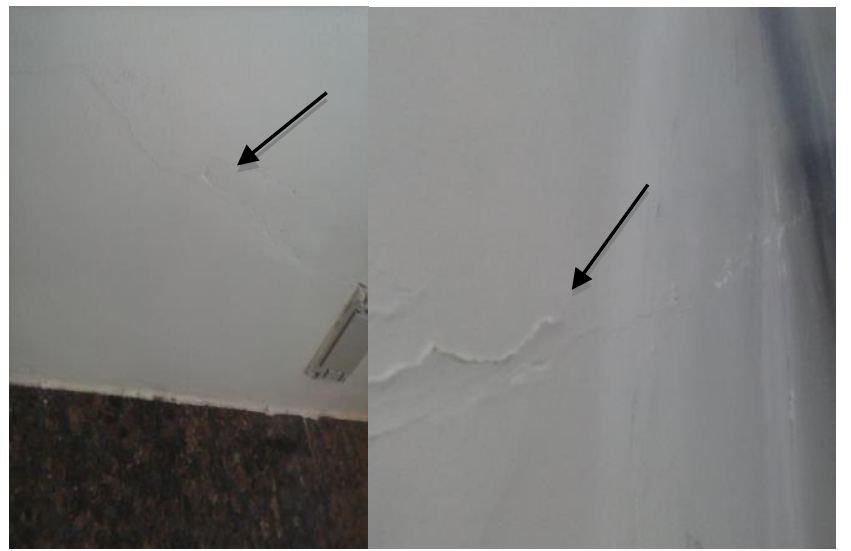

Figura 7: Fissura nas paredes de alvenaria do terceiro pavimento causados pelas movimentações diferenciais. 
Outra tipologia de fissura que foi identificada nas salas de aula pode ser observada na Figura 8, estando presente em 4 (quatro) salas de aula, a abertura deste tipo de problema não superou 1,0 mm, podendo assim também em alguns casos ser classificadas como trincas.

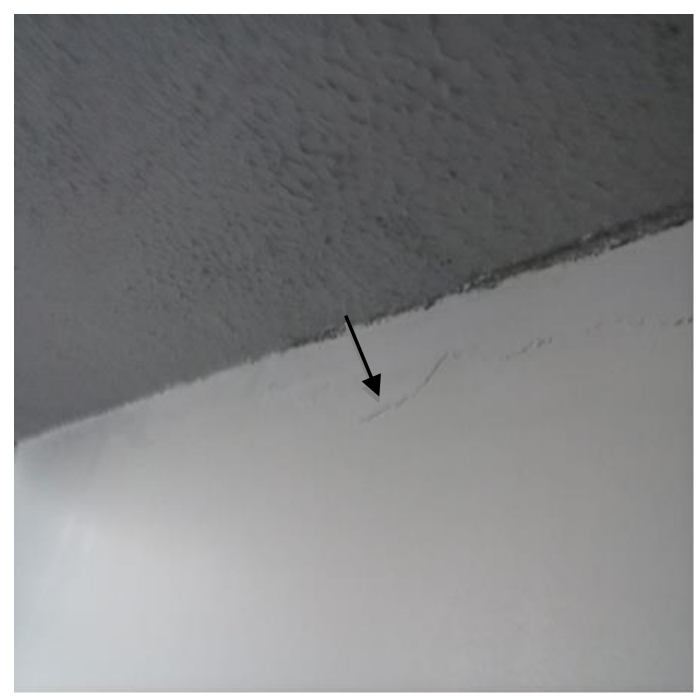

Figura 8: Fissura nas paredes de alvenaria do terceiro pavimento causados pelas movimentações térmicas diferenciais.

Por este pavimento ser de cobertura a dilatação térmica da laje é muito comum, o abaulamento e o surgimento desta fissura é o resultado da diferença de temperatura externa e interna, esta diferença de temperatura gera tensões de cisalhamento e tração na parede de alvenaria que resultam neste processo de fissuração (THOMAZ, 1989). Um esquema que representa esse tipo de manifestação patológica pode ser observado na Figura 9.

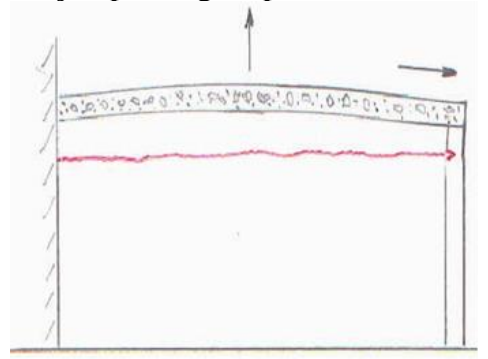

Figura 9: Esquema representativo de fissuração causada por movimentação térmica na laje.

Fonte: THOMAZ (1989).

A fissuração presente na alvenaria gerada pela movimentação térmica da laje de cobertura poderia ter sido evitada com alguns cuidados, assim indica-se que em lajes de cobertura alguns cuidados sejam tomados a fim de amenizar os efeitos térmicos nestes elementos, conforme cita Thomaz (1989):

$>$ Execução de um isolamento térmico eficaz sobre a laje;

$>$ Elevar o caimento do telhado;

$>$ Executar ventilação cruzadas a fim de possibilitar as trocas térmicas de ar;

> Pintar, se possível, o telhado da cor branca a fim de melhorar a reflexão do calor.

Os cuidados elencados anteriormente previnem o surgimento destas fissuras, porém não eliminam por definitivo a possibilidade de sua manifestação. De acordo com o exposto, o aparecimento desta fissura pode ser atribuído a um erro de projeto devido à falta de medidas preventivas e pode ser classificada com um grau de risco mínimo.

Na edificação também foram identificados problemas com infiltração. O processo de infiltração é comum e gera muitas manifestações patológicas, ou seja, um problema que ocorre em diversas edificações, tal situação é de fácil percepção e prejudica extremamente o aspecto estético da edificação, no pavimento em análise o problema ocorre em todas as 23 (vinte e três) salas, no corredor, banheiros e escadas. O que se observa na Figura 10 é o resultado da manifestação desse problema, com a infiltração e percolação da água da chuva o revestimento das paredes descola. 


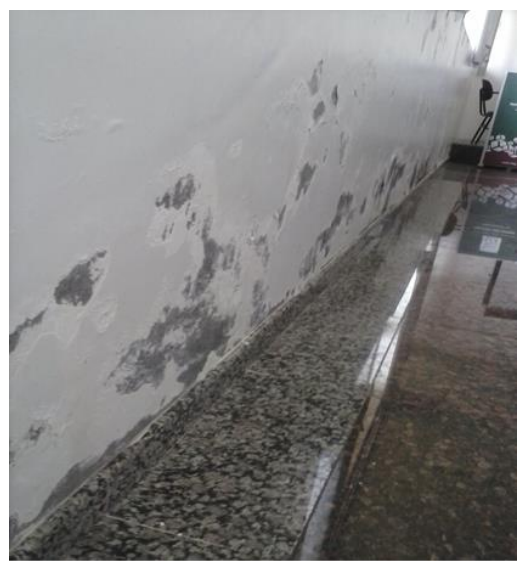

Figura 10: Aspecto da parede prejudicada pelo processo de infiltração.

Nas paredes das salas de aula não há passagem de tubulações hidráulicas, assim o problema não tem origem de vazamentos, logo a água que causa esta manifestação patológica é derivada da chuva e infiltra-se na parede principalmente pelo surgimento de fissuras na área externa nas juntas de assentamento do revestimento cerâmico de pastilhas. Outra origem da infiltração também se relaciona ao fato de que nas janelas não foram utilizadas pingadeiras, dispositivo que evita com que a água acumule e escorra junto à parede. Observa-se na Figura 11 o estado de grande parte do revestimento cerâmico nos peitoris das janelas.

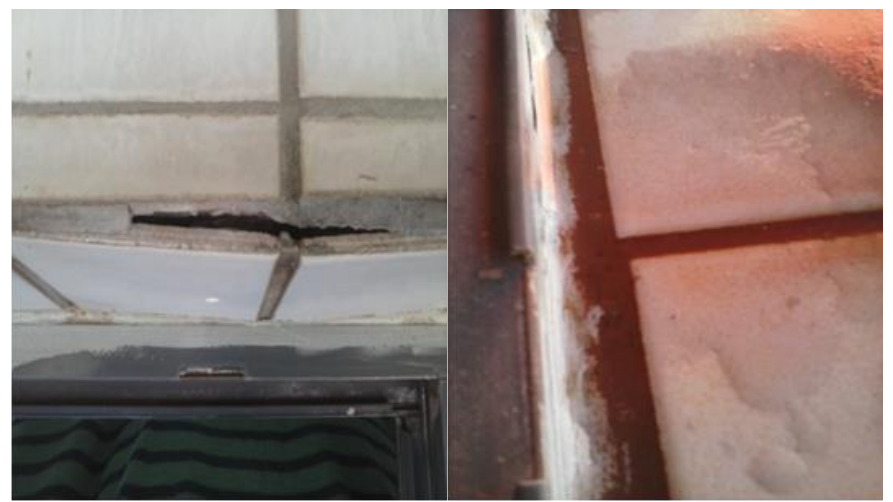

Figura 11: Estado de descolamento de pastilhas no revestimento externo e acúmulo de água nos peitoris.

Constatou-se que em várias salas de aula o revestimento cerâmico do peitoril encontrava-se conforme apresentado na Figura 11, assim a água da chuva consegue infiltrar pela parede e causando os danos conforme apresentado na Figura 10. Observou-se ainda que conforme registro da Figura 11 a água permanece acumulada no peitoril da janela, este registro foi realizado após o término de uma precipitação chuvosa, demonstrou-se assim que o desnível do peitoril foi executado de forma invertida, pois a água não deveria ficar acumulada neste local. Esse acúmulo associado com o processo de descolamento do revestimento possibilita a infiltração da água da chuva o que proporciona os problemas demonstrados anteriormente.

Para resolução deste problema patológico indicou-se a recuperação e cobrimento das juntas de assentamento do revestimento cerâmico externo juntamente com a aplicação de impermeabilizante para evitar a infiltração. Observou-se que a instalação de pingadeiras poderia evitar grande parte do problema. Com a instalação da pingadeira a linha d'água passaria a escorrer não mais colada à parede, com isso a chance que essa água se infiltre nas pequenas fissuras do revestimento cerâmico seriam reduzidas.

Outro processo de infiltração que ocorre em alguns pontos da laje deste pavimento foi classificado com risco regular, pois se torna um pouco mais preocupante, foram registrados 12 (doze) pontos com manchas de infiltração na laje nas salas de aula e no corredor, conforme registro da Figura 12. 


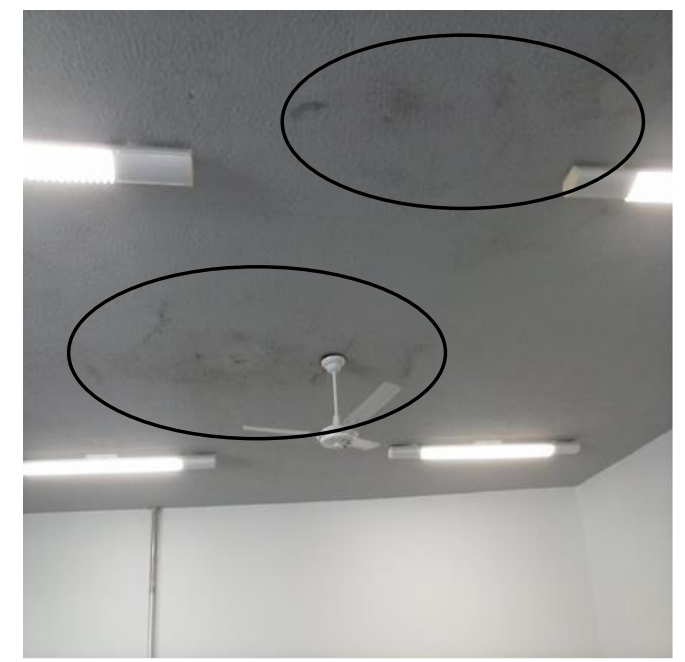

Figura 12: Presença de manchas escurecidas de colocação marrom-avermelhado na laje do terceiro pavimento.

Na Figura 12 observa-se fissuras na laje acompanhadas de uma mancha característica de infiltração, a classificação do grau de risco regular se dá pelo fato da mancha apresentar um tom marrom-avermelhado, esse tom é característico de um processo de corrosão da armadura da laje, podendo o elemento estrutural perder pontualmente o desempenho para o que foi projetado. Contudo através da inspeção visual não se pôde definir o grau e a extensão do problema, sabe-se que se a corrosão for superior a $10 \%$ da área de seção transversal da armadura tem-se uma perda considerável da resistência, podendo levar a estrutura a níveis críticos de comprometimento.

A situação relatada pode ser enquadrada como um erro de manutenção, pois se sabe que a água que provocou essa infiltração é oriunda da falta de manutenção do telhado, o qual possibilita o surgimento de goteiras que culminaram nessas manifestações patológicas. Neste caso o processo de reparo inicia-se na extinção da infiltração vinda do telhado, após isso se deve realizar a remoção de parte do concreto da laje até a armadura para verificar o comprometimento da mesma e constatação ou não da necessidade de reforço estrutural.

Em diferentes pontos do revestimento cerâmico e de granito, foram observados pontos que indicavam um processo de descolamento. Essa situação foi observada pela realização de um ensaio de percussão, onde se observou um som cavo. A manifestação patológica encontrada resulta da falta de distribuição regular da argamassa de assentamento no substrato de suporte (contra piso), este processo fragiliza a aderência do revestimento e em conjunto com a infiltração da água inicia um processo de deterioração da argamassa de assentamento causando assim o descolamento do mesmo. Alguns exemplos desse problema podem ser observados na Figura 13.

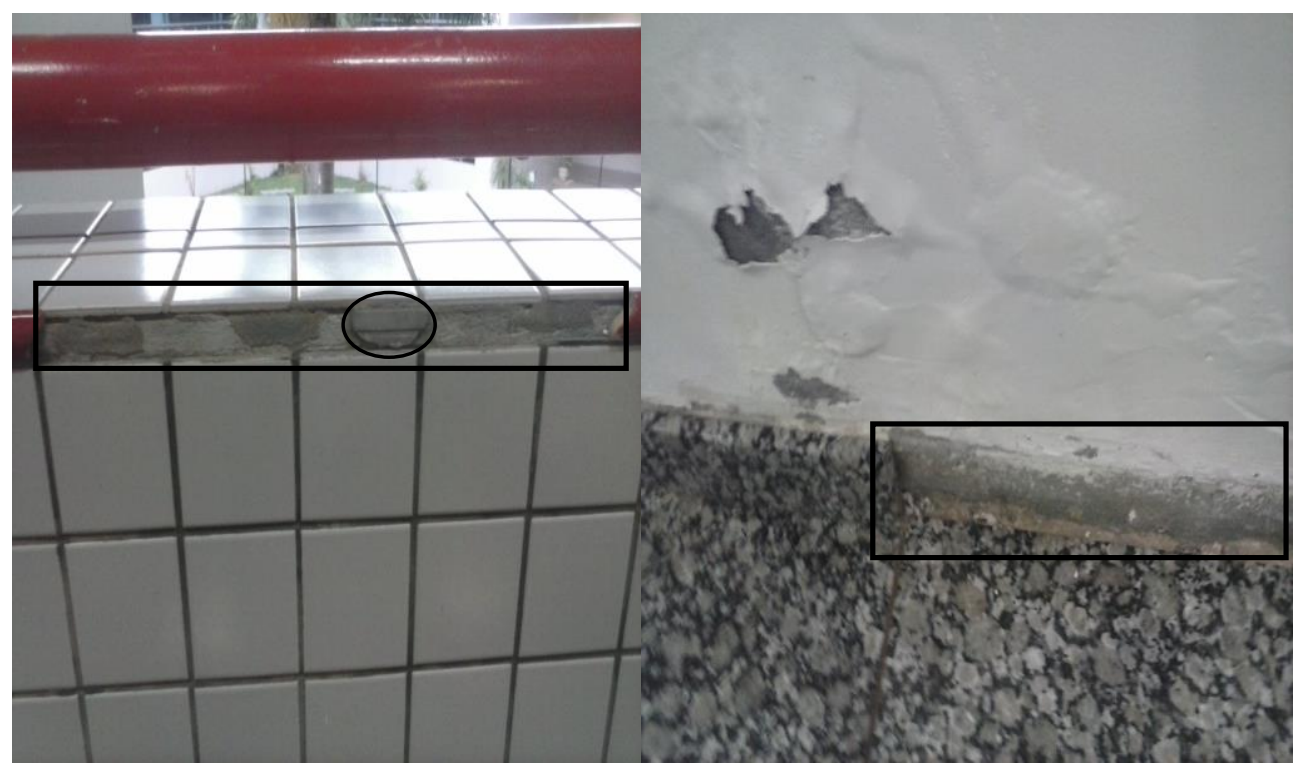

Figura 13: Pontos de descolamento do revestimento cerâmico e de granito. 
Nota-se na Figura 13 que a argamassa de assentamento foi aplicada de forma pontual em desacordo com as recomendações técnicas o mesmo acontece no rodapé. O surgimento de pequenas fissuras nas juntas de assentamento proporciona com que a água utilizada em abundância para a limpeza das salas infiltre-se no contra piso culminando na deterioração da argamassa de assentamento. O processo de assentamento inadequado e o método de limpeza utilizado proporciona a infiltração de água em fissuras que aparecem nas juntas de assentamento, o processo de limpeza é realizado com abundância de água, que propicia seu acumulo no ambiente.

Essa manifestação patológica foi classificada como um erro de execução e utilização, ainda podendo ser atribuído um grau de risco mínimo. Para o reparo deste problema deve-se retirar as peças colocadas erroneamente e fazer a reaplicação da mesma da forma correta, da mesma forma recomendou-se a manutenção das fissuras presentes no rejuntes.

Foi identificada ainda eflorescência nas lajes, pastilhas de revestimento e paredes de alvenaria do pavimento térreo, juntamente com fissura, o risco desta manifestação patológica foi classificado como mínimo, porém esta manifestação requer atenção, pois o processo que gera esse problema depende da umidade, e a umidade proporciona com que outras manifestações patológicas mais agravantes se manifestem como a corrosão da armadura de elementos de concreto armado (PAULA, 2017). Um exemplo desse problema patológico identificado no revestimento cerâmico pode ser observado na Figura 14.

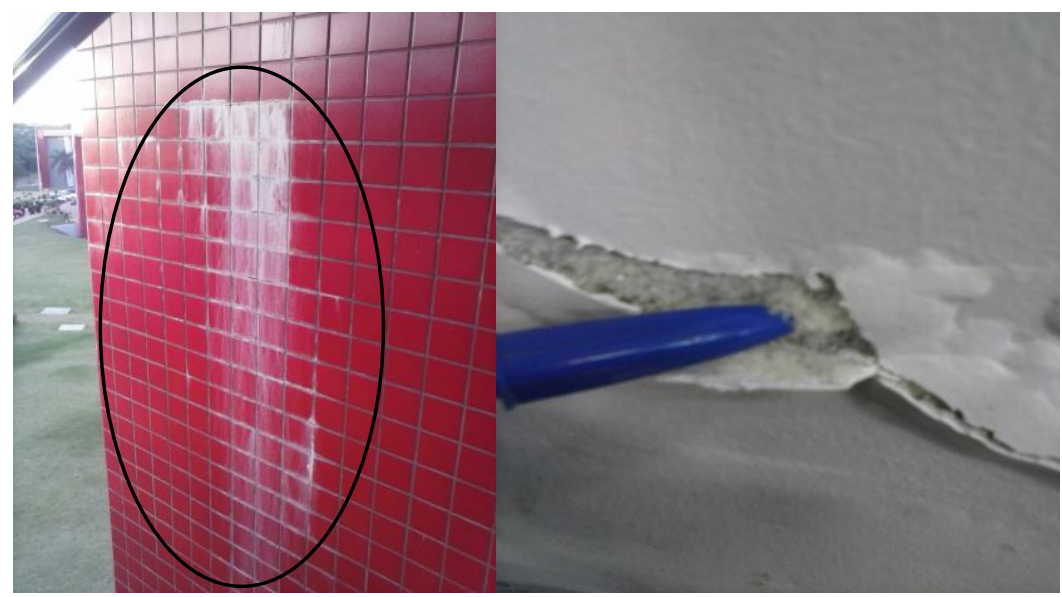

Figura 14: Eflorescências presentes no revestimento cerâmico da área externa da edificação.

Nota-se que a eflorescência deixa uma marca muito grande nas peças construtivas, causando um grande efeito negativo na estética da edificação. Definiu-se que a manifestação deste problema pode ser atribuída a um erro de execução, nos materiais utilizados ou de projeto. O reparo da eflorescência pode ser realizado com a limpeza da superfície com uma solução de ácido clorídrico a $10 \%$ e água abundante. Porém, provavelmente o problema reaparecerá até que todos os sais presentes nos materiais tenham sido eliminados, assim o processo de limpeza deve ser repetido periodicamente.

Pelos motivos relatados anteriormente a prevenção da eflorescência é vantajosa, sendo que pode ser feita através da utilização de materiais que possuam baixo teor de sais para a reação que originam este problema, na execução deve-se procurar umedecer o substrato para a colocação do revestimento evitando assim a reação do substrato de assentamento com a argamassa de assentamento, o que é comum ocorrer em dias muito quentes durante a execução do revestimento, além de procurar utilizar meios de evitarem-se infiltrações.

Para o surgimento da eflorescência é necessário que haja a presença de sais solúveis no material e água para solubilizar estes sais, sendo que após a solubilização desses sais, os mesmos tendem a migrar para a superfície da peça e formar a mancha esbranquiçada (PAULA, 2017). Na situação apresentada da Figura 14, acredita-se que a água necessária para solubilização dos sais seja proveniente de capilaridade, pois o problema manifesta-se na parte inferior da parede do térreo.

A água por um processo de capilaridade pode ascender do solo para as vigas baldrames e para a alvenaria (DUARTE, 1998 apud MAGALHÃES 2004). Na presença de água os sais solúveis ou parcialmente solúveis presentes no revestimento expandiram-se causando o rompimento do revestimento de a formação da eflorescência. Para a correção deste problema indica-se a relação da impermeabilização das vigas baldrames e a renovação do revestimento 
argamassado. A impermeabilização das vigas baldrames é um processo simples de ser executado durante o desenvolvimento da obra, porém ao ser necessário sua realização após a finalização da obra, torna-se um processo oneroso e de difícil execução (RIGHI, 2009).

\subsection{Frequência das manifestações patológicas da edificação}

A partir dos levantamentos realizados das manifestações patológicas existentes na edificação pode-se elaborar a tabulação dos dados para verificar a manifestação patológica de maior recorrência. Com as considerações tomadas conforme descrição na metodologia, adotou-se para a edificação um número de 76 unidades, assim é apresentado na Figura 15 o gráfico que numera a frequência das manifestações patológicas nos ambientes visitados da edificação.

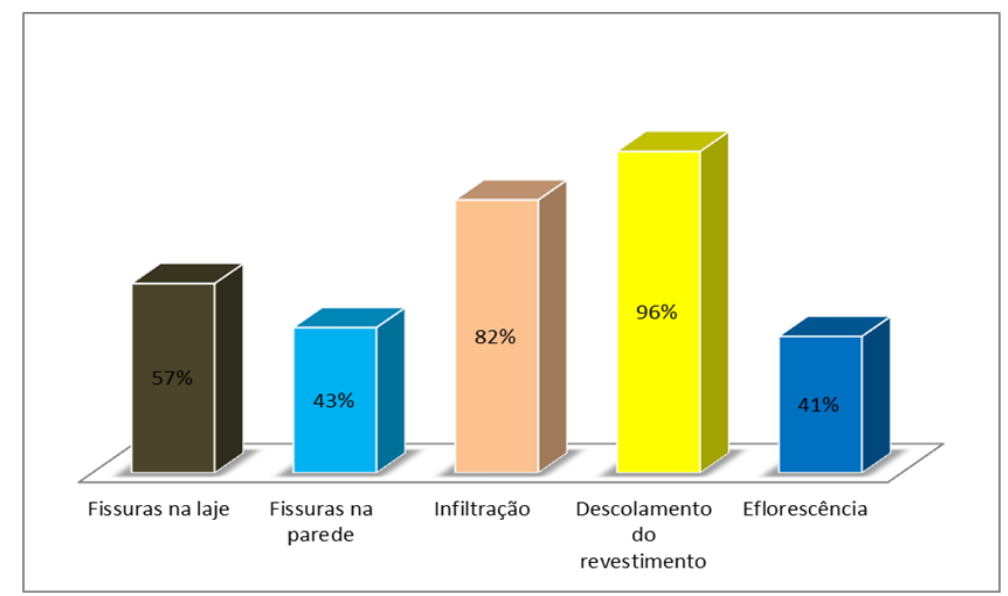

Figura 15: Gráfico da frequência dos problemas patológicos nos ambientes da edificação.

Com os resultados obtidos observa-se que $96 \%$ das unidades estão com problemas em relação ao descolamento do revestimento tendo origem na má execução dos serviços de colocação das lajotas de granito, porém esta manifestação patológica não representa um risco elevado para a estrutura, tão pouco apresenta grande impacto estético. Mas, $82 \%$ das unidades apresentam problemas relacionados à infiltração, uma pequena parte deste grupo apresenta este problema devido ao descolamento da placa de granito do piso do pavimento superior, o que juntamente com o método de limpeza utilizado favorece o processo de infiltração

Entretanto, a grande maioria das unidades afetadas pela infiltração tem como causa do problema a falta de instalação de pingadeiras nas janelas, um procedimento simples que poderia evitar muitos transtornos, visto que a infiltração gera um grande impacto estético na edificação.

\section{CONSIDERAÇÕES FINAIS}

Com esta pesquisa pode-se verificar que a grande quantidade de manifestações patológicas existentes na edificação possui grau de risco mínimo, em alguns casos as manifestações patológicas foram classificadas com grau de risco moderado/médio, essa posição reitera que em sua maioria os problemas em um primeiro momento causam maior impacto estético em desfavor da edificação e influenciam para o sentimento de insegurança dos usuários da edificação, mas não causam grandes danos estruturais na edificação.

Constatou-se que em $96 \%$ das unidades vistoriadas há descolamento do revestimento, sendo também constatado que em $82 \%$ das unidades há problemas com infiltração, foi identificado ainda que as fissuras em lajes são recorrentes em $57 \%$ das unidades visitadas, em sequência foram identificadas fissuras nas paredes em $43 \%$ das unidades e eflorescência em $41 \%$.

Ainda assim, com o levantamento realizado pode-se destacar que estas manifestações patológicas podem com o passar o tempo e a falta de tratamento proporcionar danos estruturais que podem comprometer o desempenho da estrutura, como exemplo, pode-se citar a corrosão das armaduras devido à infiltração, logo todas estas manifestações patológicas identificadas devem ser tratadas e reparadas para que sejam evitados danos maiores. 
Pode-se ainda constatar que a inspeção visual é um processo simples, porém que fornece muitas informações que possibilitam verificar o estado de conservação e a identificação de manifestações patológicas, para que estas sejam tratadas evitando-se assim maiores danos à edificação e maiores transtornos aos usuários.

\section{AGRADECIMENTOS}

Os autores gostariam de agradecer a todos que colaboraram para o desenvolvimento desse trabalho. Além disso, podese destacar o trabalho do Centro Universitário Assis Gurgacz, da cidade de Cascavel-PR no desenvolvimento da pesquisa.

\section{REFERÊNCIAS}

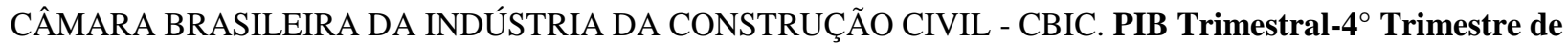
2013. Disponível em: <http://www.cbicdados.com.br/menu/home/pib-trimestral-4o-trimestre-2013>. Acesso em: 15 de out. de 2019.

INSTITUTO BRASILEIRO DE AVALIAÇÕES E PERÍCIAS. Norma de Inspeção Predial Nacional 2012. Disponível em: <http://ibape-nacional.com.br/biblioteca/wp-content/uploads/2012/12/Norma-deInspe\%C3\%A7\%C3\%A3o-Predial-IBAPE-Nacional.pdf>. Acesso em: 17 de out. de 2019.

MAGALHÃES, Ernani Freitas de. Fissuras em alvenarias: configurações típicas e levantamento de incidências no estado do Rio Grande do Sul. 2004. 180 f. Dissertação (Mestrado em Engenharia Civil) - Profissionalizante, Universidade Federal do Rio Grande do Sul, Departamento de Engenharia Civil. Porto Alegre, RS, Brasil, 2004.

PAULA, Carla Castro de. Manifestações patológicas em estruturas de concreto - Parte 1 - Introdução. CONATCON - II Congresso Nacional de Tecnologia do Concreto Online, 2017.

RACHID, Ligia Eleodora Francovg; BASE, Mariana. Levantamento das manifestações patológicas em residências familiares. Thêma et Scientia, Cascavel - Paraná, v. 1, n. 1, p. 107-119, 2011.

RIGHI. G. V. Estudo dos sistemas de impermeabilização: patologias, prevenções e correções - análise de caso. 2009. 95 f. Dissertação. (Mestrado em Engenharia Civil) - Centro de Tecnologia, Universidade Federal de Santa Maria, Departamento de Pós-Graduação em Engenharia Civil. Santa Maria, RS, Brasil, 2009.

SINDICATO DA INDÚSTRIA DA CONSTRUÇÃO CIVIL DO ESTADO DE SÃO PAULO - SINDUSCON - SP. PIB da construção deve crescer $2 \%$ em 2019 e $3 \%$ em 2020. Disponível em:

<https://economia.estadao.com.br/noticias/geral,pib-da-construcao-deve-crescer-2-em-2019-e-3-em2020,70003114838>. Acesso em: 07 de dez. de 2019.

SOUZA, V. C. M.; RIPPER, T. Patologia, recuperação e reforço de estruturas de concreto. 1. ed. São Paulo: PINI, 1998.

SOUZA, Marcos Ferreira de. Patologias causadas pela umidade nas edificações. 2008. 64 f. Monografia (Especialização em Construção Civil) - Escola de Engenharia da Universidade Federal de Minas Gerais, Departamento de Engenharia de Materiais de Construção. Belo Horizonte, MG, Brasil, 2008.

THOMAZ, E. Trincas em edifícios: causas, prevenção e recuperação. 1. ed. São Paulo: PINI, 1989.

VEDACIT. Manual técnico de recuperação de estruturas. Disponível em:

<https://www.vedanews.com.br/uploads/biblioteca/manual-tecnico-recuperacao-de-estruturas-8.pdf>. Acesso em: 10 de nov. de 2014. 